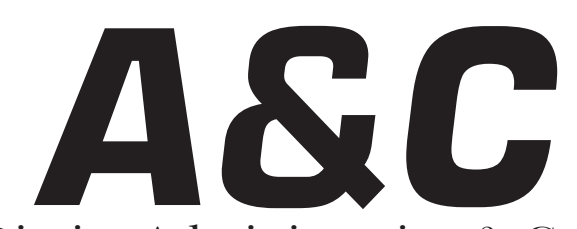

Revista de Direito Administrativo \& Constitucional

Editora Fórum

ISSN 1516-3210

\begin{tabular}{|l|l|l|l|l|l|}
\hline A\&C R. de Dir. Administrativo \& Constitucional & Belo Horizonte & ano 7 & n. 30 & p. 1-254 & out./dez. 2007 \\
\hline
\end{tabular}




\section{A\&C REVISTA DE DIREITO ADMINISTRATIVO \& CONSTITUCIONAL}

IPDA

Instituto Paranaense

de Direito Administrativo

Direção Geral

Romeu Felipe Bacellar Filho

Direção Editorial

Paulo Roberto Ferreira Motta

Direção Executiva

Emerson Gabardo

Conselho de Redação

Edgar Chiuratto Guimarães

Adriana da Costa Ricardo Schier

Célio Heitor Guimarães

\section{Conselho Editorial}

Jorge Luís Salomoni - in memoriam (Argentina)

José Carlos Abraão (Brasil)

José Eduardo Martins Cardoso (Brasil)

José Luís Said (Argentina)

José Mario Serrate Paz (Uruguai)

Juan Pablo Cajarville Peruffo (Uruguai)

Juarez Freitas (Brasil)

Julio Rodolfo Comadira - in memoriam (Argentina)

Luís Enrique Chase Plate (Paraguai)

Lúcia Valle Figueiredo (Brasil)

Manoel de Oliveira Franco Sobrinho -

in memoriam (Brasil)

in memoriam (Brasil)

Marçal Justen Filho (Brasil)

Marcelo Figueiredo (Brasil)
Márcio Cammarosano (Brasil)
Maria Cristina Cesar de Oliveira (Brasil)

Nelson Figueiredo (Brasil)

Odilon Borges Junior (Brasil)

Pascual Caiella (Argentina)

Paulo Eduardo Garrido Modesto (Brasil)

Paulo Henrique Blasi (Brasil)

Paulo Neves de Carvalho - in memoriam

(Brasil)

Paulo Ricardo Schier (Brasil)

Pedro Paulo de Almeida Dutra (Brasil)

Regina Maria Macedo Nery Ferrari (Brasil)

Rogério Gesta Leal (Brasil)

Rolando Pantoja Bauzá (Chile)

Sérgio Ferraz (Brasil)

Valmir Pontes Filho (Brasil)

Yara Stropa (Brasil)

Weida Zancaner (Brasil)

A246 A\&C Revista de Direito Administrativo \& Constitucional. ano 3, n. 11, jan./mar. 2003. Belo Horizonte: Fórum, 2003.

Trimestral

ano 1, n. 1, 1999 até ano 2, n.10, 2002 publicada pela

Editora Juruá em Curitiba

ISSN 1516-3210

1. Direito Administrativo. 2. Direito Constitucional.

I. Fórum.

CDD: 342 CDU: 33.342

(C) Editora Fórum Ltda. 2007

Todos os direitos reservados. É proibida a reprodução total ou parcial, de qualquer forma ou por qualquer meio eletrônico ou mecânico, inclusive através de processos xerográficos, de fotocópias ou de gravação, sem permissão por escrito do possuidor dos direitos de cópias (Lei n 9.610, de 19.02.1998).

Editora Fórum Ltda

Av. Afonso Pena, 2770 - 15\%16 andar - Funcionários

CEP 30130-007 - Belo Horizonte/MG - Brasil

Tel.: 08007043737

Internet: www.editoraforum.com.br

e-mail: editoraforum@editoraforum.com.br
Editor responsável: Luís Cláudio Rodrigues Ferreira Coordenação editorial: Olga M. A. Sousa

Pesquisa jurídica: Fátima Ribeiro - OAB/MG 74868

Revisora: Bárbara Christiane

Projeto gráfico: Luis Alberto Pimenta

Diagramação: Marcelo Belico

Bibliotecária: Alessandra Rodrigues da Silva -

CRB 2459 - 6 ${ }^{a}$ região

Os conceitos e opiniões expressas nos trabalhos assinados são de responsabilidade exclusiva de seus autores.

Impressa no Brasil / Printed in Brazil

Distribuída em todo o Território Nacional 


\title{
Sistema de controle interno: perspectiva gerencial e o princípio da eficiência
}

\begin{abstract}
Rodrigo Pironti Aguirre de Castro
Mestre em Direito Econômico e Social pela Pontifícia Universidade Católica do Paraná. Vice-presidente do Foro Mundial de Jóvenes Administrativistas. Membro do Instituto de Jovens Juristas Ibero-Americano. Professor do MBA em Gestão Pública da OPET. Professor da Escola Superior de Advocacia. Professor da Escola Superior de Polícia Civil e Professor do Instituto de Direito Romeu Felipe Bacellar Filho. Autor das obras: Processo Administrativo e Controle da Atividade Regulatória (ed. Fórum, 2005) e Sistema de Controle Interno: uma perspectiva do modelo de gestão pública gerencial (ed. Fórum, 2007). Coordenador executivo da obra Direito Administrativo Contemporâneo - estudos em homenagem ao prof. Manoel de Oliveira Franco Sobrinho (ed. Fórum, 2004) e organizador da obra Serviços Públicos - estudos dirigidos (ed. Fórum, 2007).
\end{abstract}

Palavras-chave: Administração Pública gerencial. Controle. Princípio da eficiência.

Preliminarmente, note-se que os temas da administração pública gerencial, do controle de resultados e do princípio da eficiência possuem, no presente estudo, relação direta e inequívoca.

Procura-se, com esta proposta, despertar a relevância do entendimento de que o direito administrativo sofreu alterações consideráveis nos últimos anos, mormente com a Reforma do Estado, e que o ponto alto dessas transformações foi uma nova concepção de controle, fulcrado na gestão gerencial e no princípio da eficiência.

Para que se trace uma noção detalhada de todo esse contexto, veja-se o que versava o Plano Diretor da Reforma do Aparelho do Estado (1995):

A reforma do aparelho do Estado passa a ser orientada predominantemente pelos valores da eficiência e qualidade na prestação dos serviços públicos e pelo desenvolvimento de uma cultura gerencial nas organizações. A administração pública gerencial constitui um avanço, e até certo ponto um rompimento com a Administração Pública burocrática. Isto não significa, entretanto, que negue todos os seus princípios. Pelo contrário. A administração pública gerencial está apoiada na anterior, da qual conserva, embora flexibilizando alguns de seus princípios fundamentais, como a admissão segundo critérios rígidos de mérito, a existência de um sistema estruturado e universal de remuneração, as carreiras, a avaliação constante de desempenho, o treinamento sistemático. $A$ diferença fundamental está na forma de controle, que deixa de se basear nos processos para se concentrar nos resultados, e não na rigorosa profissionalização da Administração Pública, que continua um princípio fundamental. [...] O paradigma gerencial contemporâneo, fundamentado nos princípios de confiança e descentralização da decisão, exige formas flexíveis de gestão, horizontalização de estruturas, des-

A\&C R. de Dir. Administrativo \& Constitucional, Belo Horizonte, ano 7, n. 30, p. 63-72, out./dez. 2007 
centralizações de funções, incentivos à criatividade. Contrapõe-se à ideologia do formalismo e do rigor técnico da burocracia tradicional. À avaliação sistemática, à recompensa pelo desempenho, e à capacitação permanente, acrescentam-se os princípios da orientação para o cidadão-cliente, do controle por resultados, e da competição administrada. ${ }^{12}$ (grifo nosso)

Em oposição à introdução de tais conceitos, mormente o conceito de eficiência administrativa tal como concebida no modelo gerencial, Lúcia Valle Figueiredo, aduz:

É de se perquirir o que muda com a inclusão do princípio da eficiência, pois, ao que se infere, com segurança, à Administração Pública sempre coube agir com eficiência em seus cometimentos.

Na verdade, no novo conceito instaurado de Administração Gerencial, de "cliente", em lugar de administrado, o novo "clichê" produzido pelos reformadores, fazia-se importante, até para justificar perante o país as mudanças constitucionais pretendidas, trazer ao texto o princípio da eficiência.

Tais mudanças, na verdade, redundaram em muito pouco de substancialmente novo, e em muito trabalho aos juristas para tentar compreender figuras emprestadas sobretudo do Direito Americano, absolutamente diferente do Direito brasileiro. ${ }^{3}$

Data vênia, a argumentação de que o princípio da eficiência sempre foi tido como orientador da atividade administrativa e que a concepção gerencial apenas agregou este conceito com foco secundário não pode prosperar.

Ora; a administração deve sim agir sempre de forma eficiente, porém o que requer a nova concepção da eficiência administrativa é que esse princípio seja observado de forma privilegiada no atuar do gestor público, ou seja, que a eficiência oriente todos os demais conceitos constitucionais necessários ao bom desenvolvimento da atividade administrativa e ao alcance do resultado pretendido.

Em obra primorosa sobre o tema, Gustavo Justino Oliveira ${ }^{4}$ alerta que a exposição de motivos interministerial $n^{\circ} 49 / 95$ - parte integrante da Mensagem Presidencial no 866/95 — ressalta como um dos resultados

\footnotetext{
${ }^{1}$ PLANO DIRETOR DA REFORMA DO APARELHO DO ESTADO. Brasília, 1995. p. 21-24.

${ }^{2}$ Convém ressaltar que, em virtude de todas essas transformações pelas quais passa o Direito Administrativo, muito se fala hoje em contratualização das relações por meio do contrato de gestão, com foco no controle de resultados. Nesse sentido, veja-se OLIVEIRA, Gustavo Henrique Justino de. O contrato de gestão na Administração Pública brasileira. 2005. Tese (Doutorado) - Universidade de São Paulo, São Paulo, 2005.

${ }^{3}$ FIGUEIREDO, Lúcia Valle. Controle da Administração Pública. São Paulo: Revista dos Tribunais, 1991.

${ }^{4}$ OLIVEIRA, op. cit., p. 276.
}

A\&C R. de Dir. Administrativo \& Constitucional, Belo Horizonte, ano 7, n. 30, p. 63-72, out./dez. 2007 
esperados da reforma administrativa "incorporar a dimensão da eficiência na administração pública: o aparelho de estado deverá se revelar apto a gerar mais benefícios na forma de prestação de serviço à sociedade com os recursos disponíveis, em respeito ao contribuinte". ${ }^{5} \mathrm{E}$ alerta que outro resultado almejado seria:

romper formatos gerais rígidos e uniformizadores: a reforma constitucional permitia a implantação de um novo desenho estrutural na Administração Pública brasileira que contemplará a diferenciação e a inovação no tratamento de estruturas, formas jurídicas e métodos de gestão e de controle. ${ }^{6}$ (grifo nosso)

Como visto, são indissociáveis os conceitos de Administração Pública gerencial, eficiência administrativa e controle de resultados na análise reformista brasileira.

Porém, é importante que haja uma precisa definição destes institutos, sobretudo no que tange ao regime jurídico administrativo, uma vez que fundado sob a égide das normas constitucionais. ${ }^{7}$

Muito embora se dê, nesta fase do estudo, ênfase à tratativa do modelo gerencial, reforce-se que o modelo burocrático fez parte das preocupações do Plano Diretor da Reforma do Aparelho do Estado, que dispôs:

o modelo burocrático tradicional que a Constituição de 1988 e todo sistema do direito administrativo brasileiro privilegiam está baseado no formalismo, no excesso de normas e na rigidez de procedimentos [...] a excessiva regulamentação é expressão da ênfase nas normas e processo, e ocorre em detrimento dos resultados. ${ }^{8}$

Luiz Carlos Bresser Pereira, defensor da noção de gerencialismo e crítico de uma burocracia que, segundo ele, não se logrou implementar no Brasil, aponta que

O objetivo de se instalar uma administração pública burocrática no país continua vivo, mas para que isso aconteça é necessário dar um passo além e caminhar na direção da administração pública gerencial, que engloba e flexibiliza os princípios burocráticos clássicos. ${ }^{9}$

Destaque-se que o modelo gerencial procura uma aproximação

\footnotetext{
${ }^{5}$ DIÁRIO DO SENADO FEDERAL. Brasília, 02 de dezembro de 1997. p. 26481.

${ }^{6}$ DIÁRIO DO SENADO..., op. cit., p. 26481.

7 Neste sentido veja-se CANOTILHO, José Joaquim Gomes. Direito constitucional. 5. ed. Coimbra: Almedina, 1992. p. 198

8 PLANO DIRETOR..., op. cit., p. 34

9 PEREIRA, Luiz Carlos Bresser. Da Administração Pública burocrática à gerencial. In: PEREIRA, Luiz Carlos Bresser; SPINK, Peter Kevin (Org.). Reforma do Estado e Administração Pública gerencial. Rio de Janeiro: Fundação Getulio Vargas, 1998. p. 267.
} 
entre os modelos de gestão pública e de gestão privada, na tentativa de tornar o Poder Público semelhante ao setor privado, principalmente no que tange à noção de eficiência.

Nesse sentido, Gustavo Justino Oliveira, acentuando a lição de Joan Pratis I Catalá, aduz:

à legitimidade tradicionalmente exigida das Administrações Públicas tem sido acrescentada não somente a exigência dos valores da eqüidade social e da participação, traçados pela transição ao Estado Social e Democrático de Direito, mas [...] também, a eficácia e a eficiência no uso dos recursos públicos. ${ }^{10}$

O princípio da eficiência, com a Emenda Constitucional no 19/98, foi elevado a princípio constitucional, inserto na norma do artigo 37 da Constituição da República.

A partir de então, com o princípio da eficiência positivado no texto constitucional, aumenta-se seu espectro, passa a conformar tanto a noção de eficiência quanto eficácia da atuação administrativa, ou seja, o princípio da eficiência preocupa-se com os meios empregados e com o alcance de seus resultados, uma vez que não constitui um fim em si mesmo e deve estar corroborado por todos os demais princípios do texto constitucional.

Seria ilógico, neste sentido, permitir que pelo princípio da eficiência fosse possível a aprovação de determinado ato, por exemplo, apenas porque cumpriu seu requisito formal; é necessário também que dele se obtenha o resultado almejado. ${ }^{11}$

A eficiência pode ser entendida como uma "medida da amplitude dos meios disponibilizados para atingir um objetivo (= relação entre o resultado obtido e os meios disponibilizados para atingi-lo)" ${ }^{12}$

Na busca pela definição jurídica do termo, José Afonso da Silva re-

\footnotetext{
10 PRATIS I CATALÁ, Joan. Direito e gerenciamento nas administrações públicas: notas sobre a crise e renovação dos respectivos paradigmas. Revista do Serviço Público, Brasília, ano 47, v. 120, n. 2, p. 23, maio/ago. 1996, apud OLIVEIRA, op. cit., p. 279

${ }^{11}$ Em sentido contrário, do qual se discorda, veja-se, CHIAVENATO, Idalberto. Introdução à teoria geral da administração. 4. ed. São Paulo: McGraw Hill, 1993. p. 238:

"A eficiência não se preocupa com os fins, mas simplesmente com os meios. O alcance dos objetivos visados não entra na esfera de competência da eficiência; é um assunto ligado à eficácia."

Acrescenta ele, à mesma página: "Contudo, nem sempre a eficácia e a eficiência andam de mãos dadas. Uma empresa pode ser eficiente em suas operações e pode não ser eficaz, ou vice-versa. Pode ser ineficiente em suas operações e, apesar disso, ser eficaz, muito embora a eficácia fosse bem melhor quando acompanhada da eficiência. Pode também não ser nem eficiente nem eficaz. O ideal seria uma empresa igualmente eficiente e eficaz". ${ }^{12}$ ALECIAN, Serge; FOUCHER, Dominique. Guia de gerenciamento no setor público. Rio de Janeiro: Revan, 2001. p. 392.

${ }^{13}$ SILVA, José Afonso da. Curso de direito constitucional positivo. 16. ed. São Paulo: Malheiros, 1999. p. 652.
} 
vela que a eficiência administrativa "consiste na organização racional dos meios e recursos humanos, materiais e institucionais para a prestação dos serviços públicos de qualidade em condições econômicas de igualdade dos consumidores". ${ }^{13} \mathrm{O}$ autor menciona, ainda, que seria a eficiência intrínseca a noção de boa administração, ou seja, a "correta gestão dos negócios públicos e no manejo dos recursos públicos". ${ }^{14}$

Alexandre de Moraes conceitua:

[...] princípio da eficiência é o que o impõe à administração pública direta e indireta e a seus agentes a persecução do bem comum, por meio do exercício de suas competências de forma imparcial, neutra, transparente, participativa, eficaz, sem burocracia e sempre em busca da qualidade, primando pela adoção de critérios legais e morais necessários para a melhor utilização possível dos recursos públicos, de maneira a evitarem-se desperdícios e garantir-se maior rentabilidade social. ${ }^{15}$

Diogo Figueiredo Moreira Neto, por sua vez, define eficiência como:

A melhor realização possível da gestão dos interesses públicos, em termos de plena satisfação dos administrados com os menores custos para a sociedade, ela se apresenta, simultaneamente, como um atributo técnico da Administração, como uma exigência ética a ser atendida, no sentido weberiano de resultados e como uma característica jurídica exigível, de boa administração dos interesses públicos. ${ }^{16}$

E complementa que com a eficiência "abandona-se a idéia de que a gestão da coisa pública basta ser eficaz, ou seja, consista apenas em desenvolver processos para produzir resultados". ${ }^{17}$

Ainda a esse respeito, o autor reforça a necessidade de mecanismos que facilitem a ação administrativa por meio de soluções de "ação concertada de entes públicos, integrando e potenciando, nos pactos de cooperação administrativos, em benefício dos administrados, meios e recursos públicos sabidamente cada vez mais escassos e limitados". ${ }^{18}$ (grifo nosso)

É nesse contexto que o princípio da eficiência é tido como uma

\footnotetext{
${ }^{14}$ SILVA, Curso..., 16. ed., p. 646.

${ }^{15}$ MORAES, Alexandre de. Reforma administrativa: emenda constitucional no 19/98. 4. ed. São Paulo: Atlas, 2001. p. 144.

${ }^{16}$ MOREIRA NETO, Diogo de Figueiredo. Curso de direito administrativo. 13. ed. Rio de Janeiro: Forense, 2003. p. 103.

${ }^{17}$ MOREIRA NETO, Diogo de Figueiredo. Coordenação gerencial na Administração Pública: Administração Pública e autonomia gerencial. Contrato de gestão. Organizações sociais. A gestão associada de serviços públicos. Consórcios e convênios de cooperação. Revista de Direito Administrativo, n. 214, p. 39, out./dez. 1998.

18 MOREIRA NETO, Coordenação..., p. 49.

${ }^{19}$ MOREIRA, Egon Bockmann. Processo administrativo: princípios constitucionais e a lei 9.784/1999. São Paulo:
} 
nova forma de controle porque a inserção do termo eficiência como princípio do caput do art. 37 da CF tem conteúdo e alcance não excludentes, mas de amplitude diversa das previsões pretéritas do termo eficiência, que não eram tão genéricas como a atual e até poderiam ser interpretadas de forma puramente econômico-administrativas e vernaculista, submetidas aos estreitos limites dos textos que as envolvem. A toda evidência é outro o desiderato normativo da EC 19, de 1988. Por isso a necessidade de enfrentar o tema sob nova ótica.

E complementa o autor:

Em primeiro lugar, acreditamos que o princípio da eficiência deve ser concebido como estritamente vinculado aos demais princípios do caput do art. 37 da CF: legalidade, moralidade, impessoalidade e publicidade. [...] Em segundo lugar, o princípio da eficiência dirige-se à maximização do respeito à dignidade da pessoa humana $\left(\mathrm{CF}, \operatorname{art}^{\circ} 1^{\circ}\right)$. Esta é a finalidade básica da Administração Pública num Estado Democrático de Direito. Não basta a inconsciente busca dos fins legais. Estes sempre devem ostentar qualidades humanas e sociais positivas. [...] Em terceiro lugar, o princípio da eficiência é diretriz de controle interna corporis da Administração Pública, correspondendo a modo de avaliação interna dos servidores. [...] Em quarto lugar, o princípio da eficiência dirige-se ao controle de metas administrativas preestabelecidas em normas legais e/ou regulamentares e contratuais. Significa dever de desenvolver, verificar e fiscalizar a atividade administrativa exercitada pela Administração, examinando-a de modo mais preciso e vinculado as disposições normativas pertinentes. Tanto mais exatas as obrigações daquele que exerce a atividade, mais viável será o controle da eficiência em seu desempenho.

Este o ponto em que o princípio da eficiência mais se assemelha à visão econômico-administrativa privada. É a relação entre os objetivos predefinidos e aqueles alcançados. Pode analisar também a atividade desempenhada, seus custos, e eventualmente, a parcela de êxito atingido. Tudo dependerá da situação fática, seu conteúdo e limites. ${ }^{19}$

Assim, com esta delimitação, muito embora o princípio da eficiência e a noção de eficiência administrativa tenham um conceito polissêmico, ou seja, compatível com várias estruturas e aplicados a inúmeras relações e ciências distintas, afastam-se desse contexto noções estritamente ligadas à economia e administração para conceituar o princípio da eficiência.

No direito brasileiro a eficiência não pode ser vista apenas como "dever irrestrito de reduzir custos e produzir superávits ou aumentar a lucratividade estatal, nem tampouco na condição de diretriz primeira 
da administração do Estado". ${ }^{20}$ Não é, pois, um princípio que autoriza “a supervalorização, no plano jurídico, dos chamados interesses públicos secundários". ${ }^{21}$

A existência do princípio da eficiência, como norma positivada no artigo 37 da Constituição da República, impõe ao intérprete uma análise em prol do cidadão, uma interpretação ampliativa de seus direitos, conformando mais uma forma de controle e um dever de probidade da atividade administrativa.

Ampliando os conceitos trazidos pelos autores supracitados e delimitando de maneira ampla o tema da eficiência administrativa, Emerson Gabardo, em obra primorosa e precursora sobre tal princípio, diverge da possibilidade de redução do princípio da eficiência a mero cumprimento formal de uma atividade e ressalta:

a eficiência não pode ser reduzida a um princípio de cumprimento de objetivos formais. Aliás, ao contrário, parece ser perfeitamente possível argüir a ineficiência de um ato por cumprir suas metas. Seria o caso, por exemplo, da adoção de metas em um contrato de gestão firmado entre entes da Administração, mas que no momento de seu cumprimento não mais estejam de acordo com a eficiência administrativa, que é vetor geral da atividade pública. ${ }^{22}$

E conjugando as lições já referidas de intersetorialização, o professor Gustavo Justino Oliveira traz o escólio de Emerson Gabardo quando aventa que "o princípio da eficiência é setorial, pois se refere exclusivamente à Administração Pública, mas está diretamente ligado ao princípio da eficiência do Estado como vetor geral (de caráter ético) do sistema constitucional", ${ }^{23}$ retirando-lhe de seu conteúdo a função meramente legitimadora de novas políticas reformistas, elevando tal princípio a "instrumento jurídico a serviço do regime administrativo consagrado constitucionalmente". ${ }^{24}$

Para além disso, Gustavo Justino Oliveira, em passagem esclarecedora, aduz:

Com efeito, constata-se que no contexto reformador brasileiro (embora de modo aparentemente mitigado) a entronização da Administração Pública

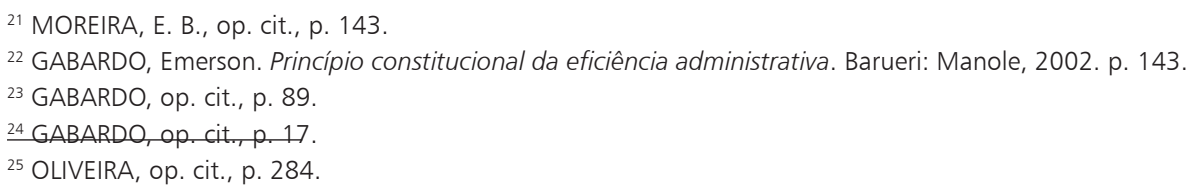


gerencial, fundada na eficiência como meio de maximização de resultados, foi encarada como uma forma de oposição e superação da Administração Pública burocrática..$^{25}$

\section{E complementa:}

Em que pesem os argumentos do discurso reformador bresseriano, assevera-se não ser possível consentir que o aparecimento do modelo gerencial visou suceder ao modelo burocrático.

Tampouco se demonstra pertinente equiparar o fenômeno da ascensão de um modelo pós-burocrático de gestão (in casu, o gerencial) àquele correspondente à história da eclosão do modelo burocrático de administração pública. Diferentemente daquele, este representou um autêntico movimento reativo, disposto a afastar e a tomar o lugar de modelos patrimonialistas de gestão pública, os quais, além de não promoverem a separação entre a propriedade pública e a propriedade privada, eram caracterizados por um exacerbado personalismo, nepotismo e fisiologismo. ${ }^{26}$

Resta claro, portanto, que o modelo gerencial — voltado à realização da eficiência administrativa - não substitui por completo o modelo burocrático, mas cumpre papel importante na evolução organizacional da sociedade, inovando e agregando conceitos antes desconhecidos, ou ao menos impensados, à Administração Pública. ${ }^{27}$

Em síntese, o modelo gerencial no Brasil não tem o condão de sobrepor-se - ou de certa maneira excluir — ao modelo burocrático, ao contrário, muito embora já seja aplicado em vários cenários desse novo contexto de Administração, tem ainda um caráter residual (experimental), constituindo-se numa projeção da Administração Pública.

Sinaliza o modelo gerencial, pois, para uma evolução no modelo de gestão dominante, incluindo técnicas e metodologias que agregam e são fundamentais para a eficiência na gestão da coisa pública.

Odete Medauar, com vistas a uma proposta de harmonização desses modelos e exaltação do controle da eficiência, ressalta que a redução da responsabilidade e a rigidez da hierarquia administrativa são desfavoráveis ao controle ${ }^{28}$ e propõe o que chama de controle de gestão, que, de maneira ampla, traduz exatamente o que este estudo convencionou chamar

\footnotetext{
${ }^{26}$ OLIVEIRA, op. cit., p. 284-285.

${ }^{27}$ Neste sentido, vide ABRUCIO, Fernando Luiz. O impacto do modelo gerencial na Administração Pública. Brasília: Imprensa Nacional, 1997 (Cadernos da ENAP, n. 10), p. 41.

28 MEDAUAR, Odete Controle da Administração Pública. São Paulo: R. dos Tribunais, 1993. p. 47.

${ }^{29}$ Frise-se que esta ponderação refere-se à tratativa do controle de gestão no âmbito da Administração Pública, ou seja, na relação "interna corporis" da Administração, não sendo considerados para fins deste estudo eventuais
}

A\&C R. de Dir. Administrativo \& Constitucional, Belo Horizonte, ano 7, n. 30, p. 63-72, out./dez. 2007 
sistema de controle interno: ${ }^{29}$

dificilmente se atingirá o ponto de abolição total do controle hierárquico, no aspecto de legalidade ou de mérito, embora se devam buscar novas técnicas de gestão e em decorrência novas técnicas de controle, de que é exemplo o controle de gestão. Evidente que um controle tão abrangente como o de gestão, que recai sobre um conjunto de atividades desenvolvidas para o atingimento de um objetivo, absorve o de legalidade e o de mérito e tem a vantagem, segundo se depreende, do acompanhamento simultâneo da atuação, com medidas corretivas a cada passo, impedindo a dispersão e o mau uso dos recursos alocados; por outro lado, quebra a rigidez da estrutura hierarquizada, sem deixar, no entanto, de observar certo escalonamento, pela existência de um agente controlador e de um chefe de projeto. Necessário se tornar tentar aplicar esta nova técnica e estudar os resultados $[\ldots]^{30}$

Nota-se, de todo o exposto, que o princípio da eficiência administrativa não pode ser entendido como um fim em si mesmo, uma vez que deve conjugar todo o contexto normativo em que está inserido e os demais princípios influentes em determinado caso.

O sistema de controle interno deve, pois, considerar todo o conjunto em que foi emanado o ato. Apenas dessa forma poderá atestar seu alcance e, por conseguinte, determinar se atingiu ou não seu ponto ótimo; em outras palavras, se foi ou não eficiente.

Para além disso, a atividade da Administração pública não pode ser controlada ou avaliada em razão, apenas, de seus resultados, pois, em determinados momentos, a análise de cada etapa do desenvolvimento da ação administrativa demonstrará a melhor satisfação do interesse público pretendido.

Não se está, com esses argumentos, a excluir a apreciação do controle de legalidade, ao contrário, o controle de legalidade e os critérios que o envolvem devem ser permanentemente avaliados. Isto é próprio de uma administração ainda hierarquizada.

Porém, privilegiar a eficiência e o controle de resultados é privilegiar o próprio sistema constitucional, uma vez que são enaltecidos os princípios do artigo 37 e do artigo 74, inciso II, da Constituição da República.

Não há dúvida, da mesma forma, que os demais dispositivos cons-

interações externas ou influxos de qualquer outra esfera ou poder.

30 MEDAUAR, Controle..., p. 49.

A\&C R. de Dir. Administrativo \& Constitucional, Belo Horizonte, ano 7, n. 30, p. 63-72, out./dez. 2007 
titucionais, como o controle de legalidade e a legalidade propriamente dita, não serão rechaçados; pelo contrário, fazem parte do mesmo núcleo constitucional (artigo 37 e 74, II, da Constituição).

O que se busca nesse novo modelo de gestão pública é a coexistência harmônica entre o controle de legalidade e o controle de eficiência e não a exclusão de qualquer um deles.

O sistema de controle interno contempla necessariamente tanto o controle de legalidade quanto o controle de resultados, devendo a este ser dado privilégio em prol da necessária eficiência na gestão da coisa pública.

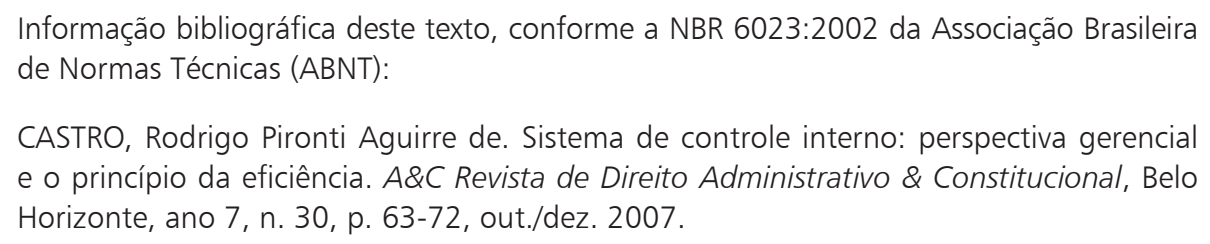

